\title{
Deterioration in Teachers' Performance: Causes and Some Remedies
}

\author{
Eliezer Yariv \\ Gordon College of Education \\ 73 Tchenechovsky St. Haifa, Israel \\ Tel: +972-4-859-0111 E-mail: elyariv@gmail.com
}

Received: January 24, 2011 Accepted: February 8, 2011 doi:10.5430/wje.v1n1p81

\begin{abstract}
Why do teachers become poor performers? In semi-structured interviews, forty elementary school principals in Israel described the personal story of one poor-performing staff member. Half of the problematic teachers were veteran teachers who faced a marked internal and external shift in mid-career. The seeds of their problems were probably planted early in their lives. Others faced a current personal crisis which impaired their performance. Poor performance was found not to correlate with any principal or teacher background variable. Neither was it connected directly with specific professional stages of a teacher's career. The discussion provides a theoretical framework and some remedies.
\end{abstract}

Keywords: Professional development, Poor performance, Teachers, Mentoring, Principals

\section{Introduction}

Problematic teachers present one of the toughest challenges school principals may ever face. Poor-performing teachers not only do not provide the expected results, but their negative behavior may distract others from doing their work and reduces staff credibility (Banfield, Richmond \& McCroskey, 2006). They consume much of the principal's time and take the place of other workers who might be of more help to the organization. Incompetent teachers are estimated to comprise about 5-10 percent of the teaching force (Bridges, 1986; Lavely, Berger \& Follman, 1992; Yariv, 2004). Despite the prevalence of this phenomenon across nations and cultures (Zhang, 2007), school administrators have enormous difficulties in improving the weak teachers' performance or dismissing them (Yariv \& Coleman, 2005; Brendan, 2005). The current study explores the reasons teachers may become poor performers.

\subsection{The antecedents of becoming a poor-performing teacher}

What causes a worker to perform poorly? Professional difficulties are a multi-faceted phenomenon, which may stem from external and internal influences (Steinmetz, 1969): a. shortcomings of the manager or the supervisor; b. shortcomings of the employee; c. outside or non-job-related influences affecting the employee.

\subsubsection{Ineffective management}

One important external source of weak performance is poor management skills and the lack of adequate supervision. Some principals lack general leadership skills or simply fail to deal effectively with their teachers' difficulties. They do not take corrective measures at early stages when such guidance might still help. Administrators also blame their predecessors who may have lacked the ability to cope with incompetent teachers, or were reluctant to confront or to give them helpful assistance.

Fidler \& Atton (1999) discuss common managerial faults related to the selection, induction, motivation, mentoring, appraisal, and development of teachers, which can cause serious future difficulties.

$<$ Table 1 about here>

Fidler \& Atton's conceptualization shows that when principals do not invest in developing their staff, some teachers' initial shortcomings may worsen. A detailed account of managerial practices that might deteriorate teachers' performance is beyond the scope of this work. Two examples, however, would help to clarify how managerial behavior contributes to the emergence and maintenance of teachers' shortcomings. Some evidence suggests that motivating is harder when workers do not deliver the expected results. Employers become more directive, allow workers little responsibility and communication appears to be one-way. In response, employees reduce their loyalty and motivation (Duarte, Goodson \& Klich, 1993). With regard to monitoring and appraisal, much evidence shows that principals do collect extensive information about their teachers, but hesitate to transmit negative feedback (Yariv, 2006). Lack of structured feedback means weak teachers attempt to function without an essential tool that might improve their performance, which causes 
the situation to deteriorate gradually.

\subsubsection{Shortcomings of the teacher}

Generally, career development follows specific stages at which the worker needs to accomplish different tasks and fulfill various requirements (Harrison, 2009). For example a novice worker is expected to become an effective member quickly, overcoming the insecurity of inexperience. Meanwhile, a late career worker is expected to take on the role of mentor, while remaining technically competent. Within American schools, the most common shortcoming cited by administrators was lack of ability and skills deficiencies. Another source of difficulties, though less prevalent, was low motivation. In a few cases, administrators portrayed the poor performers as 'trying hard but simply not getting any results' (Bridges, 1986; 1986). These teachers may not have had sufficiently developed mental capacity to meet the job requirements. Studies show that lack of meta-cognitive capabilities (Kruger \& Dunning, 1999 ), as much as a lack of emotional skills, especially with regard to unrealistically high self-esteem (Heatherton \& Vohs, 2000 ), prevent people from perceiving overt and hidden messages about their performance.

Low motivation and weak skills were not the only sources of teachers' difficulties in the classrooms. In nearly half of the cases in Bridges' (1986) studies, teachers suffered from some type of personal disorder or pathology that adversely affected their performance. Emotional distress, burn out, and health problems were common. Administrators were not always aware of the causes of poor performance (e.g. lack of skill or low motivation), which impeded their ability to help, since each pattern requires a different response (Bridges, 1992).

\subsubsection{Outside influences}

In addition to poor supervision and lack of teaching skills, unsatisfactory performance may occur due to outside influences. Sometimes there are sharp discontinuities and enormous leaps in professional development. Among the stages for teachers are: choosing to enter the profession the first exposure to teaching as a student-teacher, the first eighteen months of teaching, three years after taking the first job, mid-career moves, promotion and pre-retirement. These normal stages where individuals are confronted by choices and decisions are defined by Sikes, Measor and Woods as critical periods (Sikes, Measor \& Woods, 1985). In addition to professional variables that impact performance, personal events such as marriage, divorce or the birth or illness of a child, may occur. These periods may also coincide with a critical incident, a key event in an individual's life around which pivotal decisions are made. An example may be a teacher who faces serious discipline difficulties, loses her or his temper and decides to act aggressively.

The teacher's career is thus punctuated by critical incidents occurring typically within critical periods. One such period, unsurprisingly, is the initiation into teaching. Here new recruits are met with stark demands of the role in sudden and unsuspected confrontation, which challenge their existing claims to be a teacher (Sikes et al. 1985, p. 230).

The concepts of critical periods and life event model (Gitterman \& Germain, 2008) propose that whenever an individual experiences 'life change events' that require an adaptive response or coping behavior, it is followed by a stress reaction. They suggest that a stress-producing event can be positive (e.g. marriage) or negative (e.g. catastrophic illness of a partner), and the effects of these events are proposed to be additive. Perhaps the common denominator of all these aspects may be described as poor person-organization fit (Kristof, 1996), which explains how the social world affects an individual's social adjustment and physical and mental health. Its central proposition states that the resources and demands of the work environment may or may not fit the needs, goals, and abilities of the employee. When the match between the worker and the organization is poor, the level of stress increases.

\subsection{Research questions}

Compared to other aspects of educational management, relatively little thought and research has been given to the identification and assistance of poor-performing teachers (Wragg, Haynes, Wragg \& Chamberlin, 1999). The current study explores an important, but sparsely researched, subject in human resources management:

- What causes teachers' performance to deteriorate?

- What is the relationship between external factors, such as changes in school management or family events, and internal factors, such as personal capabilities and mental health?

\section{Research Method}

The current study is based on a mixed method (Cohen, Manion \& Morrison, 2000) in which the data is collected through interviews. Qualitative analysis is best suited to the exploration of complicated issues such as interrelationships, emotional reactions and cognitive processes. Meanwhile, categorizing the data into small and simple definitions enables the use of statistical operations and provides some insights about the quantitative aspects of the subject. 


\subsection{Sample}

Forty principals who work in 40 elementary schools were sampled. Using systematic probability sampling, each fourth school was selected from a full list of elementary schools of the Ministry of Education in the Haifa district.. The principals were 40 to 50 years old, most of them (85 percent) women, who had been working, on average, for over twenty years (M-23.3, SD- 6.6). Five of the forty principals administered more than one school.

The 'critical incident technique' (Flanagan, 1954) was used to sample the cases of challenging teachers. This technique is based on the premise that a subject matter expert (SME) describes incidents in which an employee has been very ineffective. The principals were asked to select an extreme case ('critical') of a poor-performing teacher and report about it in detail. Such a sampling method is neither random nor representative; yet, the relatively large number of cases enables both qualitative and quantitative examinations.

\subsection{Tools}

Our semi-structured interview consisted of sections containing demographic and personal details (e.g. years of work, marital status, etc.), closed questions (e.g. 'Did you send her/him a letter?') and sections that include broader categories (e.g. 'Please mark which of the eight criteria of teachers' shortcomings are applicable to the worker you describe'). The interview also included fully open-ended questions (e.g. 'Describe what measures you took in chronological order '). The answers to the closed questions were coded by 'yes' (1) or 'no' (0). More open-ended questions (e.g. 'What did you do when you noticed the teacher's problems?') were analyzed by content analysis. These categories were coded along a range of numerical categories (e.g. 'burn out' (1) 'low motivation' (2) etc.. Efforts were invested to ensure reliability (e.g. answers were not coded simultaneously in two categories). The quantitative translation of the qualitative data enabled the identification of the frequencies of each category of the statistical analysis. The frequencies, for example, of 11 teachers out of the 40 cases who appeared to have personal or personality disorders were presented as a ratio of 27 percent ( numbers were rounded to the nearest lower digit.

\subsection{Procedure and ethical aspects}

Requesting school principals to spend precious time during 'normal' school days in discussing a sensitive topic for research purposes is a challenging task. The research procedure encouraged cooperation and protected the confidentiality of the principals and the identification of the schools, as well as the privacy of the teachers the main personal and ethical concern related to discussing with the principal about one of his or her teacher's shortcomings., which may elicit negative feelings toward that worker. Therefore, all the principals were reminded in a letter about their professional responsibilities to ensure that the research would have no ill effects on the teachers. In follow-up telephone calls, the principals were asked to what extent the interview had changed their relations with the teachers and all of them responded that it had not. The research methodology enabled no further verification of this subject.

\section{Results}

Many factors may turn a worker into a successful or a failing one. Sometimes, the same situation (e.g. a 'difficult class') might drive one teacher to double her efforts, while her colleague might give up. Further, in many cases, neither the teacher nor the principals are aware of what exactly has led to deterioration, while in others, they prefer to cover up what they do know. Often, the causes of poor performance are interwoven and unraveling them may seem somewhat arbitrary. Based on the principals' answers and the theoretical conceptualization, three main sources of difficulties were discerned: a. improper management and poor supervision, b. shortcomings of the teacher and c. outside or non-job-related influences affecting the teacher.

\subsection{Improper management and poor supervision}

The principal's point of view, attitudes and personality clearly assume a significant role in defining, and sometimes intensifying, a teacher's difficulties. A mature principal who believes in self-efficacy would respond differently than a principal whose management style is more protective. Often, a new principal brings a different set of values and expectations that may clash with a teacher's previous habits.

She was a very immature person with childish behavior. The former principal fully backed her (as she did the rest of the staff) and the teacher was accustomed not to take responsibility. Whenever she felt distressed or insulted, she came to my office to complain (School 17).

About 20 percent of the cases were explained, in part, by the poor management and lack of supervision of previous administrators. In many cases, principals preferred to lay the blame on their former colleagues or on the inspectors from the Ministry of Education who granted tenure without careful examination.

In several other cases, failure may occur when the right person is placed in the wrong position or vice versa. Placement 
of teachers entails the most delicate decisions principals make each year. It is a zero-sum game where all the empty holes must be filled with the available personnel. In some cases, changing a teacher's position significantly improved his or her performance. Although principals preferred to emphasize the teachers' failures, their fingerprints, with regard to poor management, were left on the scene. Other factors, such as novice teachers, difficult pupils, complicated tasks, a critical community, to mention several factors, were found to have a limited influence on teachers' performance. According to the principals, only 20 percent of the teachers had to cope with unruly pupils or a 'difficult class.'

\subsection{Shortcoming of the employee}

\subsubsection{Lack of knowledge and experience}

It takes a teacher who arrives at a school several years to adopt the teaching methods prevalent in that school and to become immersed within the school culture and accustomed to the local traditions. About 27 percent of the cases portrayed young teachers who had been working only a few years and did not (yet) fit into the school's educational scheme. The negative correlation with age ( $\mathrm{r}-.33)$, with the total years of experience $(\mathrm{r}-.40)$ and especially with the number of years the teacher has been working in the same school $(\mathrm{r}-.44)$ suggest that novice teachers have only a very limited time-slot in which to improve their ability.

A young teacher who had moved with her husband and small baby to a nearby village arrived at the school a few days before the beginning of the school year. The inspector had suggested she inquire about a job. Since the teacher impressed the principal as being a warm person, and due to an urgent need to fill a position as homeroom teacher for the sixth grade, the principal accepted her with only a short interview about her little experience. It was clear from the beginning that her residence was located far from the school and she would later prefer to move to a school that was geographically closer. In the principal's view, the sixth grade class was a superb group with a mix of excellent and weak students. Yet, the teacher was not accustomed to the local organizational culture, and she was not prepared for the task. Difficulties communicating with the pupils, and especially, bitter criticism by the parents, devastated her. The vast amount of assistance she received did not bear the expected fruits, so the next year, to everyone's relief, she moved to a school nearer her home. The principal reflected that despite the teacher's proper skills and personality, her personal situation combined with the school's characteristics led to the failure (School 26).

Besides the lack of experience, the remote location of the teacher's residence is certainly another important reason for her failure. To some degree, her case also reflects the principal's carelessness, which can be a sign of poor management.

\subsubsection{Perceived incompetence}

"Lack of ability" is a broad and relative criterion and principals were sometimes confused as to what exactly it meant. The symptoms covered a wide range of difficulties, such as lack of ability to learn and the desire for assistance. Perceived incompetence accounted for 27 percent of the cases, and did not correlate with age or experience, but rather mildly with gender and grade level. More male teachers ( $r-.21)$ and more lower grade teachers $(r-.20)$ were perceived as incompetent. These teachers could be described as lacking in intelligence ( $r$.54). They invest much effort ( $\mathrm{r}-.19)$ but gain in return poor achievement ( $\mathrm{r} .20)$ and many discipline problems ( $\mathrm{r} .25)$, apparently due to poor teaching ( $\mathrm{r} .25)$ and aggressiveness ( $\mathrm{r}$.30).

A 57-year-old English teacher who emigrated from the former Soviet Union had tremendous difficulties in adjusting to the Israeli educational system. Despite high qualifications, she had difficulties in using the Hebrew language, continued to use conservative teaching methods and demanded strict discipline. The pupils did not understand her explanations and were afraid of her harsh sanctions and insulting remarks. Despite the pupils' and other colleagues' complaints, the principal felt helpless due to the shortage of English teachers and the superintendent's reluctance to assist (School 4).

Perceived incompetence reflects a consistent gap between the the capabilities to perform the job and the demands of the job. It usually emerges in the initial phases of the teacher's career, but it may occur in cases of an abrupt change, when the teacher has difficulty in acquiring new demands and practices.

\subsubsection{Decreased motivation}

Low motivation accounted for almost 40 percent of the cases, and it may stem from several sources, not necessarily related to being a lazy person. Such is the case when a teacher and a principal's temperament are diametrically opposed. What seems proper to one may seem too slow to the other. Further, sometimes the principal's initial wrong impression of a lazy teacher may become a self-fulfilling prophecy. The principal may reduce the workload of the teacher, believing he or she is unable to deliver the expected results. The teacher may 'read' the message behind the act and work even more slowly. Sometimes, changing positions can revive a seemingly idle worker, as in the case of the second-grade teacher who was forced to teach a fifth-grade class. 
For several years, a 49-year-old teacher had been negotiating with the principal about early retirement. Her lack of motivation was evident in every corner of her classroom - the broken furniture, the dirty floor and the walls that were covered with old and worn decorations. She set no boundaries for her students and spoke arrogantly to parents and colleagues (who preferred to distance themselves from her). She seldom came to staff meetings and refrained from initiating the organization of school events. Instead, she devoted most of her time and energy to her private practice of alternative medicine. Only upon receiving an offer from the principal to teach a second grade class with several brilliant students, did the new challenge appeal to her and worked miraculously to turn things around (School 13).

Low motivation may be defined both as a symptom, such as poor class management (as with the 2nd-grade teacher), and as a cause that initiates a downward spiral of deteriorated interpersonal relations and poor outcomes that may lead to the dismissal of the worker.

\title{
3.2.4 Personal and personality disorders
}

When asked whether the problematic teacher had a personal disorder (e.g. burn out, severe emotional distress, personal inflexibility, mental illness, alcoholism, etc.), over half of the principals (55 percent) answered positively. The disorders most frequently mentioned were burnout and stress. Stressful conditions and burnout are usually measured on the basis of the workers' self report (Maslach, Schaufeli \& Leiter, 2001), but here it was based on the principal's impression. About one third of the challenging teachers, most of them veterans with over 20 years of experience, were reported as suffering from burn out. Other mental health problems were not mentioned specifically.

\subsection{External influences}

Teachers' unsatisfactory performance could be attributed, in half of the cases, to serious difficulties in their lives. Sometimes encountering one difficulty perpetuated a downward spiral.

\begin{abstract}
Esther (40) was a talented teacher with an excellent reputation who moved to work at the school several years ago. She taught humanities in most of the grades. As a person with strong opinions, she soon became involved in intrigues and rumors. The teachers resented her criticism and avoided her companionship. Like the short distance runner, whatever job she did not like frustrated her immediately. She was impatient with the principal, who taught her daughter. Things began to deteriorate when her mother died of cancer. Esther became aggressive; she demanded that the school purchase expensive teaching materials for her, asked to change her position and to increase her salary. By mid-year, she decided to move to another school, but accepted the request to continue teaching here. A few months later, she bitterly criticized the principal and tried to incite teachers to mutiny, but in vain. During the second winter season, she was absent many days due to back pain. By the end of that year, Esther moved to another school. Throughout this period, her family suffered serious financial difficulties, while her husband frequently threatened divorce (School 25).
\end{abstract}

Marital difficulties and financial problems were commonplace. Several of the teachers had gone through difficult divorces, while other teachers, like Esther, were distracted by continual turmoil in their marriages. Bridges (1992) emphasized this point:

These teachers may have been caught in some vicious cycle in which the problems at home and work fed on one another and created a downward spiral in both settings (p. 12).

\subsection{Patterns of difficulties}

According to the principals, the causes of the teachers' difficulties varied tremendously from case to case. Several teachers had to cope with only one unfavorable condition, while others suffered no less than four, five and even six different sources of hardships (M- 2.8; SD 1.8). But, to what extent did the teachers in this study experience vicious cycles as described by Bridges? Did certain shortcomings and difficulties actually cluster into a group of troubles?

$<$ Table 2 about here>

The results show that three quarters of the combinations were not statistically significant. This means that encountering one difficulty is not necessarily connected to experiencing other kinds of hardship. Further, five out of the seven statistically significant combinations were negative, thereby supporting the distinctiveness of each difficulty in itself. It seems that each kind of antecedent was uniquely related to a different group of teachers (e.g. motivated but inexperienced teachers, veteran burn out teachers) and that explains the lack of statistical connection. Of special interest is the positive medium to high correlation ( $\mathrm{r}$.50) between two 'internal' categories - mental disorders (e.g. stress, burn out) and personal difficulties (e.g. marital crisis). It is probable that feelings of anxiety and depression interact and augment poor interrelations with staff and students. It also emerges that whenever personal difficulties arise, teachers increase their efforts (correlated negatively with lack of motivation).

Poor performance was found not to correlate with any of the principal or teacher background variables (e.g. gender, age, education). Neither was it connected directly with specific professional stages of a teacher's career (Huberman, 
Thompson \& Weiland, 1997), even though some stages, like entering the profession, and the 'conservative' stage (Huberman, 1993) appeared to be more 'vulnerable' to difficulties and stagnation. 'Incompetence,' as such, accounted for about one quarter of the challenging teachers. Based on their accounts, principals determined the incapable teachers to be the least sharp and wise worker on their staff. Another quarter of the teachers were novice workers who were posted in unfavorable positions. In these cases, without supportive guidance, while facing growing pressures from parents and students, the principals apparently did not have enough patience. They preferred to send the teacher elsewhere. The principals' reports seem to be somewhat biased. They underestimated their contribution to the problems, mainly with regard to poor inspection and mistaken decisions in human resource management. Principals did not always know about teachers' personal problems outside school. Meanwhile, they put much of the blame on the teachers' personality and shortcomings, while some of the teachers simply did not have enough experience or enough assistance when facing a personal crisis.

In summary, the emerging picture, according to the principals' accounts, is that half of the problematic teachers happened to be veteran teachers who faced a marked internal and external shift in the middle of their careers. The roots of their problems, mainly personality traits such as inflexibility, lack of intelligence, insensitivity and lack of motivation, were probably present early in their lives. Some were reasonably good teachers until a crisis occurred - the sickness and death of a family member, financial difficulties, getting divorced and the like. Ineffective attempts to cope with that change brought them to a very low point, both professionally and personally. Meanwhile, other teachers performed unsatisfactorily from the start, but gained tenure through apathetic inspectors and were supported for a long time by "considerate" principals. When a new principal arrived, the rules changed and the teachers' shortcomings were exposed. Some teachers tried to revolt, an act which intensified their conflict with the new principal.

\section{Discussion}

Analyzing the antecedents which brought teachers and principals to their current unwanted situation brings to mind two unifying themes: first, a poor fit between the organization and the worker. Person-Environment fit theories deal with research on job satisfaction, job stress, vocational choice, recruitment and selection, and organizational climate and culture (Edwards, 2008). When such essential elements as skills or occupational tendencies of the worker do not fit the job demands, it may lead to ineffective work, frustration, burn out and premature leaving. For example, one principal was convinced that one of her teachers' styles was suitable for high school students, rather than third-grade pupils. The second theme is the negative influence of changes in a worker's life. Many teachers considered as problematic, faced a personal or professional crisis at the time, which intensified earlier unfavorable conditions. For example, a 50-year-old teacher had to take care of a terminally ill parent. The physical and mental burden of treating a loved one, the ongoing stress and the subsequent bereavement, seriously damaged her professional functioning. Such antecedents may feed each other and create a downward spiral.

\subsection{Poor teacher-school fit}

Worker-environment fit is a complicated and 'conceptually ambiguous phenomenon' (Edwards, 2008, p. 215). Its clinical diagnosis is tentative and is often reached post factum, after a change has been made. When some of the teachers in this study were described as 'inflexible' it could mean they no longer kept track of the demands of current practice. When they were bluntly described as 'stupid,' it could signify a poor fit between their cognitive capabilities and the school's cognitive climate (Cools, Van den Broeck \& Bouckenooghe, 2009). Since the principals knew little about the early stages of the teachers' professional lives, college study, selection or induction into teaching, we have limited information to assess the initial match between these teachers and the profession of teaching. The evidence in this study raises concern about some poor-performing teachers who simply passed by sleepy administrators and managed to sneak through the half-opened doors on their way to tenure. Worse, there were administrators who betrayed their duty. One principal, for example, admitted she manipulated her inspector's impressions as he observed a young teacher. That poor-performing teacher, who enjoyed the favor of her supervisor, was later granted tenure. More detailed enquiry of the teachers' stories is needed to better assess the match between teachers' skills and their work demands.

The result of poor fit and working in a stressful environment can lead to feelings of mental and physical exhaustion. We saw that one third to one half of the challenging teachers sampled were described as suffering from burnout and other mental symptoms of stress. Teacher burnout has been widely reviewed and studied (Friedman, 2000). The core burnout dimensions of emotional exhaustion, depersonalization and feelings of low personal accomplishment stem from various aspects of school climate (Grayson \& Alvarez, 2008), workload, time pressure, relations with parents (Skaalvik \& Skaalvik, 2008) and other factors. Since measures of burnout at work are solely based on the worker's reports (Maslach, Schaufeli \& Leiter, 2001), the absence of the teacher's perspective prevents an analysis of it, why and when these difficulties emerged. 


\subsection{Changes and Crises}

The concepts of critical periods and life event model (Gitterman \& Germain, 2008) clearly apply to the findings in this study, where half of the problematic teachers faced marked changes in their lives. It is hard to estimate what impact these significant events (e.g. divorce, financial difficulties) had on the teachers' functioning, but given that other teachers who may have experienced similar events continued to work with no marked influence, we can only suggest that major stressful life events did not create incompetence, but rather intensified weaknesses and difficulties. Among these influences, two frequent professional changes appeared to have a unique impact: the replacement of a principal and the phenomenon of immigrant teachers. When a new principal arrived (or when the teacher transferred to another school), well-balanced relations with the former principal and the staff were reopened. It became a turning point for many teachers, some of who advanced, while others lost their place. Novice principals, even those who preferred to conserve the school's traditions, tried to correct what seemed to them as poor performance. No wonder forty percent of the teachers in this study remained less than three years in their current school before leaving to another. The poor teacher-principal match did not succeed and ended with in separation. The second change refers to teachers who emigrated with their families from the former Soviet Union and experienced significant difficulties in coping with the cultural and professional transition.

\subsection{Assisting and developing teachers: practical recommendations}

Identifying and assisting teachers who face professional and personal hardships is a vital aspect of effective management, yet it is perceived as difficult and, therefore, tends to be ignored or sidelined by management and researchers. Further, school administrators often hold a set of generally false assumptions (Bullough, 2008) about teacher motivation (increased competition promises higher levels of teacher and school performance), intentions (teachers are selfish and self-serving), the nature and difficulty of the work of teaching (almost anyone can teach), evidence of performance (test scores are meaningful representations of essential school aims), the power of schooling (that setting school standards and tinkering with curricula resolves persistent social problems) and responsibility (teachers are wholly responsible for student learning). The assumptions, therefore, that drive reform are grounded in a putative, rather than a positive, psychology, a view fixated on weaknesses and deficits, rather than on learning and building on strengths. Combating teachers' professional and personal hardships requires a concerted multi-level systematic and persistent program. Such intervention may be handled, according to Armstrong and Baron (2005) along five consecutive steps: a) identify and agree upon the problem, b) establish the reason(s) for underperformance, c) decide and agree on the action required, D) resource this action, e.g. training and e) monitor performance and provide feedback.

The following recommendations, which are based on the author's experience and the limited research available, focus on the fourth stage - training and counseling.

4.3.1 Coping with hardships: A course for principals. Principals should be trained to identify teachers' weaknesses; how to cope with unfavorable (but rather expected) situations, like confronting a rebellious teacher or meeting with a violent parent who complains about her child's teacher. Such training may include understanding their own style of problem solving, learning various methods of conflict management, participating in simulations and having organizational counseling resources at hand.

4.3.2 Inspectors' guidance. In a study on assisting poor performing workers, Goodhew, Cammock, \& Hamilton (2008) found that while front-line managers had consistent understanding of what constitutes poor performance, they were markedly less clear about what the organization would regard as effective performance and how to achieve it. It is essential that inspectors of the Ministry of Education develop policies and strategies, as well as actively consulting principals on how to handle deteriorating professional performance.

4.3.3 Workshops for principals. Despite the inherent differences in power relations between managers and teachers, an open dialogue based upon mutual trust would help identify the true causes of poor teacher performance (Rhodes \& Beneicke, 2003). An opportunity to work through such difficulties took place in a weekly five-session workshop for 8 elementary and junior high school principals led by the author. The program included studying general aspects of human resource management with emphasis on managing challenging workers, presenting the findings of this and other studies, asking participants to present and analyze cases of staff members who suffer difficulties and studying and practicing how to give effective feedback. The participants were encouraged to discuss their shortcomings with these staff members, explore their professional and personal needs and offer assistance. Reflecting upon their experiences, the workshop participants conceded that their perceptions of the failing teacher had changed from a one-sided, mostly negative impression to an understanding of how complicated each case is. They also emphasized the central role of practicing giving feedback. The extensive practice during the workshop helped improve mutual relations and clarify hidden causes of failure and obstacles. 
4.3.4 Collegial peer support, coaching and mentoring mechanisms have been shown to achieve some success in remediating poor teacher performance. Yariv and Coleman (2005) describe a case of a principal who initiated cooperation between a talented teacher and her failing colleague, first by asking them to teach the same subject matter. Then, in order not to decrease the weak teacher's confidence (who suffered severe health problems) and to create a common working system, she encouraged them to attend out-of-school courses. These courses on heterogeneous teaching and on learning disabilities matched their pupils' needs. Later, the principal asked the inspector, without specifying the reason, to observe both teachers. She also visited their classes and talked with them. This course of action proved very effective.

4.3.5 Mentoring, Flesch (2005) argues that mentoring has traditionally focused on trainees and newly qualified teachers. There is no established, effective mentoring procedure to help teachers who have worked for longer periods of time and who are still not coping after all available help has been offered. Using an intensive mentoring (IM) framework, she WHO??? joined 13 elementary school teachers for two weeks, throughout the day, encouraging them to improve their practice through reflection and by example. During IM, each teacher experiences a series of emotional stages that involve coming to terms with the loss of old habits, ideas and notions. No less than 10 out of 13 participants showed marked improvement during and after the intensive intervention.

4.3.6 Consulting services. The Israeli Teachers' Union has developed consulting services in the form of hot lines and regional offices that provide inexpensive psychotherapy, marital counseling and professional guidance. These services are meant to overcome frequent obstacles that block the road to improvement, such as poor relationships with colleagues or severe psychological distress that could benefit from the intervention of a mental health professional.

\subsection{Limitations}

As an exploratory study, the major weakness, in terms of validity, was the reliance on one source of information, the principals' description of the teacher's case. Their perceptions were most likely partial and certainly subjective. In a situation in which the cases were so varied, when the teachers and others' perspectives were hardly represented, and when the passage of time continuously changed the relations and the situations (either healing the wounds or intensifying the pain), drawing an objective picture and reaching solid conclusions became more difficult. A different perspective may well have been obtained if the teachers, who were the subjects of the interviews, had also been interviewed.

In summary, within the two or three decades of a teachers' career, many changes may occur. Some are expected and planned for, like getting a job or giving birth, while others are not (Day, Sammons, Gu, Kington \& Stobart, 2009). Since we live in an extremely dynamic era, with only limited control over how many things develop, no one can guarantee continuous professional success and a happy ever after life. Most workers, but not all, overcome daily difficulties and cope effectively with major life events. As a subject that is seldom studied and investigated for the first time in Israeli schools, this study revealed how personal and organizational factors contribute to intensify the vicious cycle. Several suggestions were offered for how organizations, in general, and managers, in particular, can improve these unfavorable situations. Bullough (2008) argues that, at this moment in time, as the lives of teachers are being researched, there may be no more important task than championing the cause of teaches and making clear the connections between their well-being and the well-being of the children in their care. It is hoped that this paper will encourage practitioners and researchers to begin to systematically inquire into a subject that is often regarded as taboo (Wragg, Haynes, Wragg \& Chamberlin, 1999).

\section{References}

Armstrong, M. \& Baron, A. (2005). Managing performance: Performance Management in Action. London: Chartered Institute of Personnel and Development.

Banfield, S. R., Richmond, V. P., \& McCroskey, J. C. (2006). The effect of teacher misbehaviors on teacher credibility and affect for the teacher. Communication Education, 55, 63-71.

Bullough, R. (2008). The writing of teachers' lives: Where personal troubles and social issues meet. Teacher Education Quarterly, 35, 7-26.

Brendan, P. M. (2005). Teachers' perceptions of professional incompetence and barriers to the dismissal process. Journal of Personnel Evaluation in Education, 18, 309-325. doi:10.1007/s11092-007-9026-7, http://dx.doi.org/10.1007/s11092-007-9026-7 
Bridges. E, M. (1992). The Incompetent Teacher: Managerial Response (rev.). London: The Falmer Press.

Bridges. E, M. (1986). The Incompetent Teacher: The Challenge and the Response (rev.). London: The Falmer Press.

Cohen, L., Manion, L., \& Morrison, K. (2000). Research Methods in Education (5th edition). London: Routledge.

Day, C., Sammons, P., Gu, Q., Kington, A. \& Stobart, G. (2009). Committed for life? Variation teachers work, lives and effectiveness, In M. Bayer; U. Brinkkjaer; H. Plauborg and S. Rolls (Eds.). Teacher' Career Trajectories and Work Lives (3, 49-70). Springer

Duarte, N. T., Goodson, J. R., \& Klich, N. R. (1993). How do I like thee? Let me appraise the ways. Journal of Organizational Behavior, 14, 239-249.

Edwards, J. R. (2008). Person-environment fit in organizations: An assessment of theoretical progress. The Academy of Management Annals, 2, 167-230. doi:10.1080/19416520802211503, http://dx.doi.org/10.1080/19416520802211503

Fidler, B., \& Atton, T. (1999). Poorly Performing Staff in Schools and How to Manage Them. London: Routledge.

Flanagan, J. C. (1954). The critical incident technique. Psychological Bulletin, 31(4), pp. 123-154.

Flesch, G. (2005). Mentoring the non-coping teacher: A preliminary study. Journal of Education for Teaching, 31, 69-86.

Friedman, I. A. (2000). Burnout in teachers: Shattered dreams of impeccable professional performance. Journal of Clinical Psychology, 56, 595-606.

Gitterman, A., \& Germain, C. B. (2008). The life Model of Social Work Practice: Advances in Theory and Practice. New York: Columbia University Press.

Goodhew, G. W., Cammock, P. A., \& Hamilton, R. T. (2008). The management of poor performance by front-line managers. The Journal of Management Development, 27, 951-962. doi:10.1108/02621710810901291, http://dx.doi.org/10.1108/02621710810901291

Grayson , J. L., \& Alvarez, H. K. (2008). School climate factors relating to teacher burnout: A mediator model. Teaching and Teacher Education. 24, 1349-1363. doi:10.1016/j.tate.2007.06.005, http://dx.doi.org/10.1016/j.tate.2007.06.005

Harrison, R. (2009). Learning and Development. New York: McGraw-Hill.

Heatherton, T. F., \& Vohs, K. D. (2000). Interpersonal evaluations following threats to self: Role of self-esteem. Journal of Personality and Social Psychology, 78, 725-736.

Huberman, M. (1993). The Lives of Teachers. New York: Teachers College Press.

Huberman, M., \& Thompson, C. C., \& Weiland, S. (1997). Perspectives on the teaching career, In B. J. Biddle, T. Good, I. F. Goodson (Eds.). International Handbook of Teachers and Teaching, (pp. 11-77). London: Kluwer Academic Publishers.

Kristof, A. I. (1996), Person-organization fit: An integrative review of its conceptualization, measurement, and implication. Personnel Psychology, 49, 1-49.

Kruger, J., \& Dunning, D. (1999), Unskilled and unaware of it: How difficulties in recognizing one's own incompetence lead to inflated self-assessment. Journal of Personality and Social Psychology, 77, 1121-1134.

Lavely, C., Berger, N., \& Follman, J. (1992). Actual incidence of incompetent teachers. Educational Research Quarterly $15,11-14$.

Maslach, C., Schaufeli, W. B., \& Leiter, M. P. (2001). Job burnout. Annual Review of Psychology, 52: 397-422.

Sikes, P. J., Measor, L., \& Woods, P. (1985). Teacher Career, Crises and Continuities. London: Falmer.

Skaalvik, E. M., \& Skaalvik, S. (2008). Does school context matter? Relations with teacher burnout and job satisfaction. Teaching and Teacher Education, 25, 518-524. doi:10.1016/j.tate.2008.12.006, http://dx.doi.org/10.1016/j.tate.2008.12.006

Rhodes, C. \& Beneicke, S. (2003). Professional development support for poorly performing teachers: challenges and opportunities for school managers in addressing teacher learning needs. Professional Development in Education, 29, 123-140.

Steinmetz, L. (1969). Managing the Marginal and Unsatisfactory Performer. MA: Addison-Wesley.

Wragg, E. C., Haynes, G. S., Wragg, C. M. \& Chamberlin, R. P. (1999). Managing Incompetent Teachers. Retrieved from http://leeds.ac.uk/educol/documents/00001235.htm. p. 27. 
Yariv.E. (2004). Challenging teachers: what difficulties do they pose to their principals. Educational Management Administration and Leadership, 32, 165-184. doi:10.1177/1741143204041881, http://dx.doi.org/10.1177/1741143204041881

Yariv, E. (2006). Mum effect: Principals' reluctance to submit negative feedback. Journal of Managerial Psychology, 21, 6, 533-546. doi:10.1108/02683940610684382, http://dx.doi.org/10.1108/02683940610684382

Yariv, E. and Coleman, M. (2005). Managing challenging teachers. International Journal of Educational Management, 19, pp.330-336. doi:10.1108/0951340510599653, http://dx.doi.org/10.1108/0951340510599653

Zhang, Q. (2007). Teacher misbehaviors as learning demotivators in college classrooms: A cross-cultural investigation in China, Germany, Japan, and the United States. Communication Education, 56, 209-221.

Table 1. Problems arising from poor staff management

\begin{tabular}{|l|l|l|}
\hline & \multicolumn{1}{|c|}{ Potential problems } & \multicolumn{1}{c|}{ Results } \\
\hline & Key skills of job not identified & Lack of capability \\
\hline Selection & Candidate's skills not matched to job & Lack of capability \\
\hline & Poor fit between candidate and school culture & Capable employee performs poorly. \\
\hline $\begin{array}{l}\text { Staff } \\
\text { Induction }\end{array}$ & Job not made clear & Parts of job undone \\
\hline & Expectations of job not clarified & Parts of job not done sufficiently well \\
\hline $\begin{array}{l}\text { Motivation } \\
\text { \& Mentoring }\end{array}$ & Work and standards not discussed & Candidate does not fit in. \\
\hline & Needed development not discussed & Poor quality work or other interest taken up \\
\hline $\begin{array}{l}\text { Staff } \\
\text { Appraisal }\end{array}$ & Work problems not discussed & Job not done or not done sufficiently well \\
\hline & Career plans not discussed & Job not done or not done sufficiently well \\
\hline $\begin{array}{l}\text { No } \\
\text { Development }\end{array}$ & Lack of professional progress & $\begin{array}{l}\text { Employee not motivated or has to devise } \\
\text { own career path unaided }\end{array}$ \\
\hline & In a 'rut' & Frustration \\
\hline
\end{tabular}

Adapted from Fidler \& Atton, 1999, pp. 14-23 
Table 2. Correlations of causes of teachers' difficulties

\begin{tabular}{|c|c|c|c|c|c|c|c|}
\hline & $\begin{array}{l}\text { Difficult } \\
\text { Class }\end{array}$ & $\begin{array}{c}\text { Poor } \\
\text { Management }\end{array}$ & $\begin{array}{c}\text { Lack of } \\
\text { Experience }\end{array}$ & $\begin{array}{l}\text { Lack of } \\
\text { Ability }\end{array}$ & $\begin{array}{c}\text { Lack of } \\
\text { Motivation }\end{array}$ & $\begin{array}{c}\text { Mental } \\
\text { Disorders }\end{array}$ & $\begin{array}{c}\text { Personal } \\
\text { Difficulties }\end{array}$ \\
\hline $\begin{array}{c}\text { Poor } \\
\text { Management }\end{array}$ & .21 & - & & & & & \\
\hline $\begin{array}{c}\text { Lack of } \\
\text { Experience }\end{array}$ & .11 & .25 & - & & & & \\
\hline $\begin{array}{l}\text { Lack of } \\
\text { Ability }\end{array}$ & -.16 & .11 & .00 & - & & & \\
\hline $\begin{array}{c}\text { Lack of } \\
\text { Motivation }\end{array}$ & $-.26 *$ & .12 & -.13 & -.24 & - & & \\
\hline $\begin{array}{c}\text { Mental } \\
\text { Disorders }\end{array}$ & .07 & .07 & $-.34 *$ & -.23 & .02 & - & \\
\hline $\begin{array}{c}\text { Personal } \\
\text { Difficulties }\end{array}$ & .12 & .12 & .05 & -.05 & $-.36 *$ & $.50 * * *$ & - \\
\hline Other & -.10 & -.10 & .13 &,$- 33 *$ & $.30 *$ & $-.28 *$ & -.21 \\
\hline
\end{tabular}

${ }^{*} \mathrm{p}<.05, * * \mathrm{p}<.01, * * * \mathrm{p}<.001$ 